\title{
Interleukin-8 and the Neutrophil Response to Mucosal Gram-negative Infection
}

\author{
William W. Agace, * Spencer R. Hedges, * Miroslav Ceska, ${ }^{*}$ and Catharina Svanborg ${ }^{*}$ \\ * Department of Medical Microbiology, Division of Clinical Immunology, Lund University, S-22362 Lund, Sweden; \\ and ${ }^{\ddagger}$ Sandoz Research Institute, A-1235 Vienna, Austria
}

\begin{abstract}
Urinary tract infections activate a mucosal inflammatory response, which includes cytokine secretion and neutrophil influx. The mechanisms involved in the neutrophil influx have not been identified. Interleukin-8, a potent chemoattractant for neutrophils, is produced by urinary tract epithelial cell lines in vitro. This study analyzed the human IL-8 response to deliberate Escherichia coli infection of the urinary tract. Urine and serum samples were obtained before and after intravesical instillation of $\boldsymbol{E}$. coli. Neutrophil numbers were determined on uncentrifuged urine, and IL-8 levels were measured by ELISA. A urinary IL-8 response was found in all patients after bacterial instillation, but no serum IL-8 was detected. There was a strong correlation between urinary IL-8 levels and urinary neutrophil numbers. The same $E$. coli strains used to colonize the patients stimulated IL-8 production in urinary tract epithelial cells. The level of IL-8 secreted by epithelial cell lines was influenced by the fimbrial properties of the $E$. coli. These results demonstrated that $E$. coli elicit a mucosal IL-8 response in humans, and suggested that IL-8 is involved in the onset of pyuria. Epithelial cells may be an important source of IL-8 during urinary tract infection. ( $J$. Clin. Invest. 1993.92:780-785.) Key words: urinary tract infection • cytokines • Escherichia coli • fimbriae • epithelial cells
\end{abstract}

\section{Introduction}

IL-8 belongs to the CXC family of chemokines, which includes NAP-1 (IL-8), NAP-2, and gro. These proteins act as powerful chemoattractants for neutrophils. The in vitro effects of IL-8 on neutrophils include chemotaxis, degranulation, trans-endothelial migration, and respiratory burst (1-4). In vivo, IL-8 induces a rapid and long lasting accumulation of neutrophils in rabbit skin (5). Human neutrophil migration into skin chambers has also been associated with the production of IL-8 (6). Although originally isolated from the culture supernatants of LPS stimulated monocytes, IL-8 has since been shown to be produced by a wide variety of cells, including lymphocytes, endothelial cells, and pulmonary epithelial cells $(1,7,8)$. We have recently shown that IL-8 is produced by urinary tract epithelial cell lines in response to stimulation with uropathogenic Escherichia coli (9).

Address correspondence to William Agace, Department of Clinical Immunology, Lund University, Lund, Sweden.

Received for publication 22 September 1992 and in revised form 23 March 1993.

J. Clin. Invest.

(c) The American Society for Clinical Investigation, Inc.

0021-9738/93/08/0780/06 \$2.00

Volume 92, August 1993, 780-785
Infections of the urinary tract activate a mucosal inflammatory response. One aspect of this response is a rapid influx of neutrophils into the urine. This occurs both in patients with urinary tract infection (UTI) ${ }^{1}$ and in individuals deliberately colonized in the urinary tract with $E$. coli $(10,11)$. Little is known about the mechanisms of neutrophil recruitment from the blood stream into the urine. We have previously shown that urinary IL-6 levels are elevated in patients with UTI (10). However, a role for IL-6 as a neutrophil chemoattractant has not been documented. We considered it more likely that a chemoattractant such as IL-8, produced at the mucosal surface, would be responsible for the neutrophil influx that occurs during UTI.

The aim of the present study was to determine whether IL-8 is secreted during UTI in humans, and to identify the cell types which might be involved in this response.

\section{Methods}

Patients. Women with a history of recurrent symptomatic UTI were colonized in the urinary tract with $E$. coli. The study was approved by the Ethical Committee at Göteborg university, Sweden. The study protocol and the outcome of the bacterial colonization have been reported elsewhere (12). Before colonization, the patients were treated with oral antibiotics to eliminate preexisting bacteriuria. Each colonization attempt consisted of bacterial instillation on three consecutive days or less if bacteriuria $\geq 10^{5} / \mathrm{ml}$. Each colonization started $5 \mathrm{~d}$ after the last antibiotic dose, to reduce the likelihood of reinfection before inoculation with the study strains. The patients were hospitalized for colonization and $24 \mathrm{~h}$ of observation. The bacterial instillation procedure was as follows: A postvoidal residual urine sample was collected by catheter and cultured to confirm the sterility of the precolonization sample. After complete evacuation of the bladder, $10 \mathrm{ml}$ of the bacterial mixture was introduced and the catheter was removed. All urine samples were collected from each voiding during the subsequent $24 \mathrm{~h}$ and daily during the first week. Urine samples were obtained at the weakly clinic visit thereafter. Daily blood samples were obtained during hospitalization. All urine samples were cultured and the urinary neutrophil count was determined on uncentrifuged urine using a Fuchs-Rosenthal chamber. There were 15 colonization attempts in eight patients. Seven colonizations were successful as defined by the presence of bacteriuria for at least $30 \mathrm{~d}$. The IL- 6 levels and neutrophil numbers in these samples have previously been reported (11). In this study, the stored urine and serum samples from six of the colonized patients were examined for IL-8 with ELISA.

Bacteria. The wild-type $E$. coli isolate, 83972 , serotype ON:KN had been carried for $3 \mathrm{y}$ by a girl with asymptomatic bacteriuria, who had shown no deterioration of renal function. E. coli 83972 was genotypically negative for the pap DNA sequences (encoding P fimbriae) and positive for the pil DNA sequences (encoding the type 1 fimbriae). Phenotypically E. coli 83972 was negative for type 1 and P-fimbrial adhesins, and did not attach to uroepithelial cells in vitro. The strain was maintained on tryptic soy agar (Difco Laboratories, Detroit, MI).

1. Abbreviations used in this paper: BSS, balanced salt solution supplemented with $0.01 \mathrm{M}$ Hepes buffer; UTI, urinary tract infection. 
E. coli Hu 1061 was the transformant of 83972 which had received the pap $_{396}$ DNA sequences encoding $P$ fimbriae. The strain was maintained on tryptic soy agar containing $10 \mu \mathrm{g} / \mathrm{ml}$ of tetracycline. The $E$. coli Hu 1053 was the transformant of 83972 which had received the pil DNA sequences encoding type 1 fimbriae. The strain was maintained on tryptic soy agar with $100 \mu \mathrm{g} / \mathrm{ml}$ of ampicillin. A mixture of the three $E$. coli strains was used for colonizations in patients $1,2,5$, colonization (i) in patient 3 , and colonization (ii) in patient 4 . A mixture of the two transformant $E$. coli 1053 and $E$. coli 1061 was used for colonization (ii) in patient 3 , colonization (i) in patient 4 , and colonization (i) in patient 6.

For in vitro stimulation of epithelial cells, each of the three $E$. coli strains were inoculated into fresh Luria broth and incubated overnight at $37^{\circ} \mathrm{C}$. The bacterial suspensions were harvested by centrifugation and resuspended in culture medium (RPMI 1640 supplemented with 2 $\mathrm{mM}$ glutamine and 5\% fetal calf serum [Gibco Ltd., Paisley, Scotland]) to a final concentration of $10^{8}$ bacteria $/ \mathrm{ml}$.

Isolation and stimulation of bladder epithelial cells. Urinary tract epithelial cells were isolated from four different male patients undergoing cystoscopy for bladder neck obstruction due to benign hyperplasia of the prostate. On each occasion the patients' bladders were irrigated with saline $(500 \mathrm{ml})$. The irrigation fluid was centrifuged at $1,000 \mathrm{~g}$ for $10 \mathrm{~min}$ (Hettich rotanta/RP centrifuge, Malmö, Sweden). The supernatant was discarded and the epithelial cell pellet $\left(\approx 5 \times 10^{4}\right.$ cells $)$ was resuspended in $2 \mathrm{ml}$ of culture medium and transferred to $2-\mathrm{ml}$ glass vials (Nunc, Roskilde, Denmark). The epithelial cells were incubated with culture medium alone or culture medium with $E$. coli 83972 (1 $\times 10^{8}$ bacteria $/ \mathrm{ml}$ ) at $37^{\circ} \mathrm{C}$ in $5 \% \mathrm{CO}_{2}$ atmosphere. Cell samples were collected before and $4 \mathrm{~h}$ after stimulation and centrifuged at $1,000 \mathrm{~g}$ for $5 \mathrm{~min}$. The epithelial cell pellet was resuspended in balanced salt solution (Gibco Ltd.) supplemented with $0.01 \mathrm{M}$ Hepes buffer (Gibco Ltd.) (BSS), washed twice in BSS, and $20 \mu \mathrm{l}$ was applied to each field of an adhesion slide and allowed to adhere electrostatically for $\mathbf{3 0} \mathrm{min}$ in a humid chamber. Intracellular IL-8 was detected by indirect immunofluorescence.

In vitro stimulation of urinary tract epithelial cell lines. The A-498 kidney (No. HTB44; American Type Culture Collection, Rockville, MD) and J82 bladder (No. HTB1; American Type Culture Collection) epithelial cell lines were grown in culture medium with $0.1 \mathrm{mg} / \mathrm{ml}$ gentamycin (Flow Laboratories, Stockholm, Sweden) as previously described (13). Cells were seeded into 24-well culture plates (Nunc) and allowed to grow to confluency before use. The cell lines were stimulated with $E$. coli $83972, E$. coli 1061 , and $E$. coli 1053 . The culture medium, containing gentamycin, was removed and replaced with gentamycinfree culture medium with or without the respective $E$. coli strain (1 $\times 10^{8}$ bacteria $/ \mathrm{ml}$ ). The cells were incubated at $37^{\circ} \mathrm{C}$ in $5 \% \mathrm{CO}_{2}$ atmosphere and supernatants were collected at zero, 2,6 , and $24 \mathrm{~h}$. The IL-8 content of the supernatants was analyzed by ELISA. Residual gentamycin was not removed as it maintained the epithelial cells viability during the experimental period by preventing further bacterial growth over the $24 \mathrm{~h}$. Cultures taken from the supernatants at $24 \mathrm{~h}$ were negative for bacterial growth. Dead bacteria are known to stimulate epithelial cytokine secretion (13).

Quantitation of $I L-8$ in patient samples and cell supernatants. IL-8 was determined using a double ligand ELISA method (14). Briefly, 96-well plates (Immuno-Plate I 96-F; Nunc) were coated with monoclonal mouse anti-human IL-8 antibodies $(5 \mu \mathrm{g} / \mathrm{ml}$; Sandoz, Vienna, Austria) diluted in carbonate buffer ( $\mathrm{pH} 9.6,100 \mu \mathrm{l}, 0.1 \mathrm{M} \mathrm{NaHCO}_{3} /$ $\mathrm{NaCO}_{3}$ ) and left overnight at $4^{\circ} \mathrm{C}$. The plates were washed (four times) in PBS with $0.05 \%$ Tween 20 (washing buffer, $\mathrm{pH} 7.4$ ). Recombinant IL-8 (Sandoz) was serially diluted ( $10-0.02 \mathrm{ng} / \mathrm{ml}$ ) in PBS with Tween 20 and 5\% FCS (dilution buffer). For the standard curve, $100 \mu \mathrm{l}$ of each dilution was added to a row of wells on the plate. Collected samples were diluted 1 in 10 in dilution buffer, and $100 \mu \mathrm{l}$ was added to the remaining wells. The plates were incubated for $2 \mathrm{~h}$ at $37^{\circ} \mathrm{C}$ in a humid chamber and then rinsed (four times) in washing buffer. Polyclonal goat anti-mouse antibody conjugated with alkaline phosphatase was added to the wells $\left(50 \mu \mathrm{l}, 5 \mu \mathrm{g} / \mathrm{ml}\right.$ ) and incubated for $2 \mathrm{~h}$ at $37^{\circ} \mathrm{C}$ in a humid chamber. Unbound conjugate was removed by washing four times and $p$-nitrophenyl phosphate in diethanolamine buffer (BioRad, GmbH, Munich, Germany) was added at a concentration of 1 $\mathrm{mg} / \mathrm{ml}$. The plates were incubated at room temperature in the dark for $30 \mathrm{~min}$. The reaction was stopped by the addition of $2 \mathrm{M} \mathrm{NaOH}$ and the absorbance was measured at $\mathbf{4 0 5} \mathrm{nm}$ in an ELISA counter (Multiskan Plus; Labsystems, Helsinki, Finland). The IL-8 activity in the samples was given in nanograms per milliliter, after calibration with the standard curve. The lower detection limit of the assay was $0.2 \mathrm{ng} / \mathrm{ml}$.

Immunofluorescence staining. The indirect immunofluorescence technique to detect cytokine production by single cells has been described (15). Briefly, the bladder epithelial cells were fixed with paraformaldehyde. Indirect immunofluorescence staining of IL-8 was performed in the presence of saponin to create cell membrane permeability and allow the passage of antibodies into cellular compartments. Irrelevant mouse $\operatorname{IgG}_{1}$ was used as a negative control. The stained cells were examined with a microscope (Microphot-FX; Nikon, Tokyo, Japan) equipped with a $100-W$ mercury lamp (Osram, Berlin-Munich, Germany) and a Ploem-pac with filter sets for FITC. To prevent ultraviolet light quenching, buffered glycerol (ACO, Stockholm, Sweden) containing 2\% 1,4-diazabicyclo-[2.2.2] octane (Sigma Immunochemicals, St. Louis, MO) was used as a mounting medium.

Bacterial adherence. $\mathrm{J} 82$ and A-498 epithelial cells were grown to confluency on 8-well slide flasks ( Nunc) in culture medium with gentamycin. The culture medium with gentamycin was removed and replaced with gentamycin-free medium and each of the three $E$. coli strains $\left(1 \times 10^{8}\right.$ bacteria $\left./ \mathrm{ml}\right)$. The cells were incubated at $37^{\circ} \mathrm{C}$ in a $5 \%$ $\mathrm{CO}_{2}$ atmosphere for $3 \mathrm{~h}$. Supernatants were removed and the epithelial cells were washed 10 times with BSS to remove nonadhering bacteria. The cells were then fixed with methanol for $5 \mathrm{~min}$ and stained with May-Grünewald stain. The number of attached bacteria was counted by interference contrast microscopy. Adherence is given as the mean number of bacteria per epithelial cell ( 40 epithelial cells counted).

Statistical analysis. Samples were compared using the Wilcoxon's signed rank test.

\section{Results}

IL-8 response in the colonized patients. The urinary IL-8 activity was analysed by ELISA in samples obtained before and after intravesical instillation of $E$. coli. IL-8 was not detectable in the precolonization samples $(<0.2 \mathrm{ng} / \mathrm{ml}$; Table I). IL-8 was detected in the urine of all the patients after instillation of $E$. coli. Two patients ( 2 and 5) had peak urinary IL-8 levels $>5 \mathrm{ng} / \mathrm{ml}$ (high responders) and four patients had peak IL-8 levels $<3$ $\mathrm{ng} / \mathrm{ml}$ (low responders) (Table I). The kinetics of the urinary IL-8 response are shown in Fig. $1, A$ and $B$, for the two high responder patients, and Fig. 1, $C$ and $D$, for two of the low responder patients. IL-8 was detected in the urine of the high responders as early as $3 \mathrm{~h}$ after bacterial instillation. Peak IL-8 levels were reached after $6-10 \mathrm{~h}$. In patient 2 there was one IL-8 peak after each instillation of $E$. coli (Fig. $1 A$ ). In patient 5 , IL-8 appeared to be secreted intermittently (Fig. $1 B$ ). The increase in urinary IL-8 levels in the low responder patients followed bacterial instillation (Fig. 1, $C$ and $D$ ).

The serum IL-8 response to bacterial instillation was analyzed in 15 samples obtained from the high responder patients ( 2 and 5 ) during the colonization period. There was no detectable IL- 8 in any of the samples obtained before or after bacterial instillation.

Urinary neutrophil response. The number of neutrophils was counted in each of the urine samples. The precolonization samples contained $<5$ neutrophils $/ \mathrm{mm}^{3}$. After bacterial in- 
Table I. Urinary IL-8 and Neutrophil Response to Intravesical Inoculation of E. coli

\begin{tabular}{lcrr}
\hline $\begin{array}{c}\text { Patient } \\
\text { (colonization) }\end{array}$ & Instillation* & Urinary IL-8 & Urinary neutrophils \\
\hline & & $n g / m l$ & cells $/ \mathbf{m m}^{3}$ \\
$1^{\prime \prime}$ & $(1)$ & 1.3 & 166 \\
& $(2)$ & 0.7 & 240 \\
& $(3)$ & 2.8 & 670 \\
2 (i)" & $(1)$ & 20.5 & 7,040 \\
& $(2)$ & 6.2 & 3,840 \\
& $(3)$ & 2.6 & 228 \\
2 (ii)" & $(1)$ & 9.1 & 8,800 \\
3 (i)" & $(1)$ & 0.5 & 124 \\
& $(2)$ & 0.5 & 870 \\
& $(3)$ & $<0.2$ & 225 \\
3 (ii)" & $(1)$ & 0.9 & 145 \\
& $(2)$ & 0.8 & 338 \\
4 (i)" & $(1)$ & 0.9 & 30 \\
& $(2)$ & $<0.2$ & 98 \\
4 (ii)" & $(1)$ & $<0.2$ & 276 \\
& $(2)$ & 1.4 & 11,000 \\
$5^{\prime \prime}$ & $(1)$ & 5.8 & 76 \\
$6^{\prime \prime}$ & $(1)$ & 0.7 & \\
& & &
\end{tabular}

* Each colonization consisted of one to three instillations of bacteria. Colonizations were performed with a mixture of $E$. coli strains 83972, 1061 , and 1053 (") or a mixture of E. coli strains 1061 and 1053 ("). The colonization was regarded as completed when a positive urine culture was obtained $\left(\geq 10^{5}\right.$ bacteria/ml). The lower detection limit of the assay was $0.2 \mathrm{ng} / \mathrm{ml}$ (standard error $0.07 \mathrm{ng} / \mathrm{ml}$ ). 10 samples taken before colonization contained $<0.2 \mathrm{ng} / \mathrm{ml}$ of IL-8 $(\mathrm{SE}=0)$. ₹ The peak IL- 8 activity measured during the 24 -h period after bacterial instillation. The peak neutrophil counts observed during the 24-h period after bacterial instillation. stillation a neutrophil response was observed in all the colonized individuals. There was considerable individual variation in the peak neutrophil numbers (Table I). Two patients ( 2 and 5) had high $\left(>7,000\right.$ cells $\left./ \mathrm{mm}^{3}\right)$, and four patients had low neutrophil peak counts $\left(<1,000\right.$ cells $\left./ \mathrm{mm}^{3}\right)$.

Correlation between the IL-8 and neutrophil responses. The high IL-8 and neutrophil responses occurred in the same two patients ( 2 and 5; Fig. 1, $A$ and $B$ ). The correlation coefficient between their urinary IL-8 levels and neutrophil numbers was $0.6(P<0.001)$. The peak neutrophil numbers occurred at the same time as the peak levels of urinary IL-8. The four patients with low IL-8 levels had peak urinary neutrophil numbers ranging from 30 to 900 cells $/ \mathrm{mm}^{3}$. The correlation between their urinary neutrophil numbers and IL-8 levels was weak ( $r$ $=0.3, P<0.001)$. The correlation between urinary IL-8 levels and neutrophil numbers in all samples obtained from the six patients was $0.7(P<0.001)$.

The possible association between IL-8, and the previously measured bacterial numbers and IL-6 levels $(11,12)$ was investigated in the patients. There was no significant correlation between the urinary IL- 8 levels and the bacterial numbers in the urine. There was no apparent threshold level of bacteria above which IL- 8 secretion occurred. There was no significant correlation between the IL- 8 and IL- 6 levels in the individual samples.

IL-8 production by bladder epithelial cells. The analysis of the early urinary IL-8 response showed that IL-8 could be present in urine before the neutrophil influx (Fig. $1 A$ ). We therefore examined urinary tract epithelial cells as a possible source of IL-8. Bladder epithelial cells isolated on four separate occasions from four different patients were stimulated with $E$. coli 83972. 100-300 cells were counted in each sample. On each occasion, $>70 \%$ of epithelial cells stained for IL-8 after $4 \mathrm{~h}$ of stimulation (Fig. $2 A$ ). Unstimulated bladder epithelial cells did not stain for IL-8 (Fig. $2 \mathrm{~B}$ ).
A

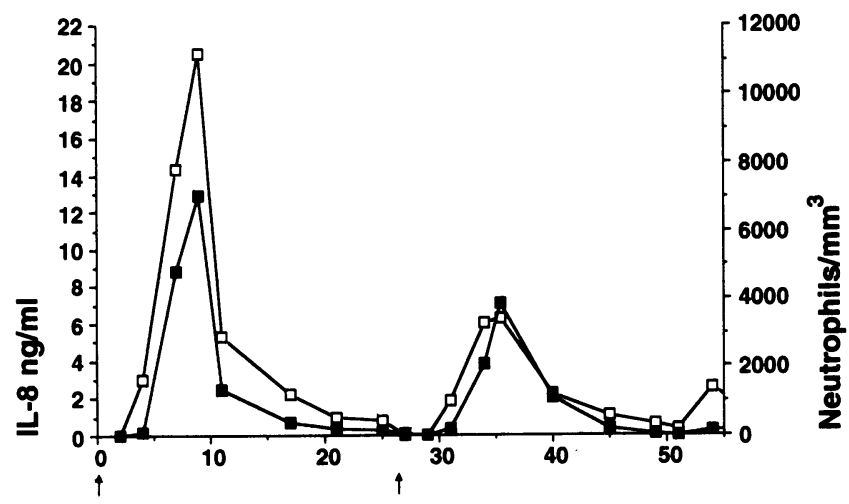

C

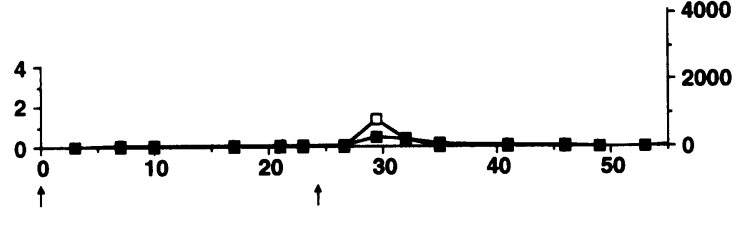

Time/Hours
B
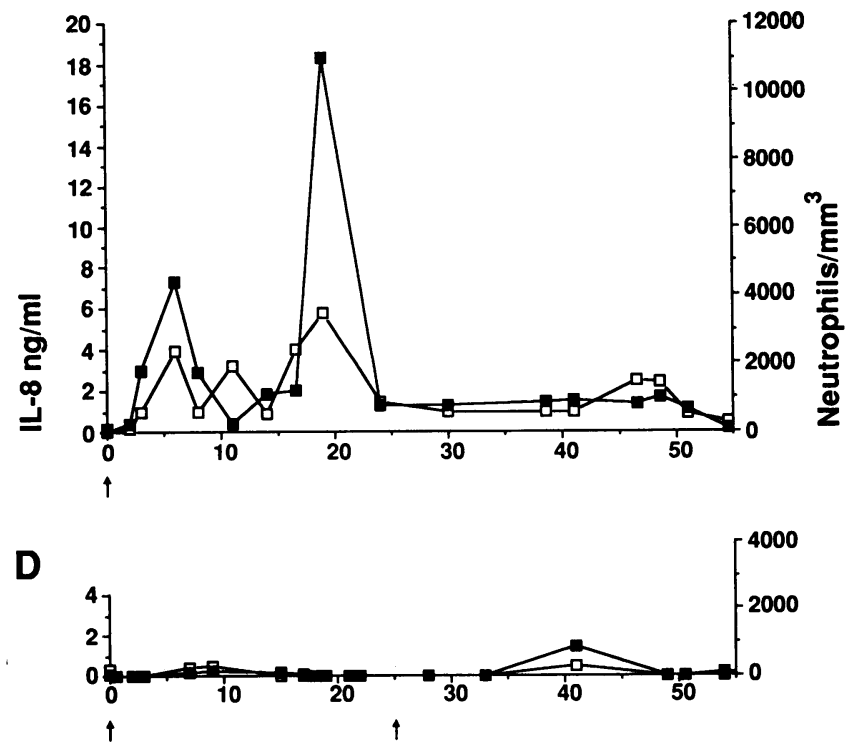

Time/Hours

Figure 1. The kinetics of the IL-8 and neutrophil response in four patients after instillation with E. coli 83972, E. coli Hu1061, and E. coli Hu1053. $A$ and $B$ show results from the two patients with a high neutrophil response. $C$ and $D$ show results from two patients with a low neutrophil response. $\longrightarrow \square-$, Levels of IL-8; $\rightarrow-$, number of neutrophils; $\uparrow$, time of bacterial instillation into the bladder of the patients. 


\section{A}
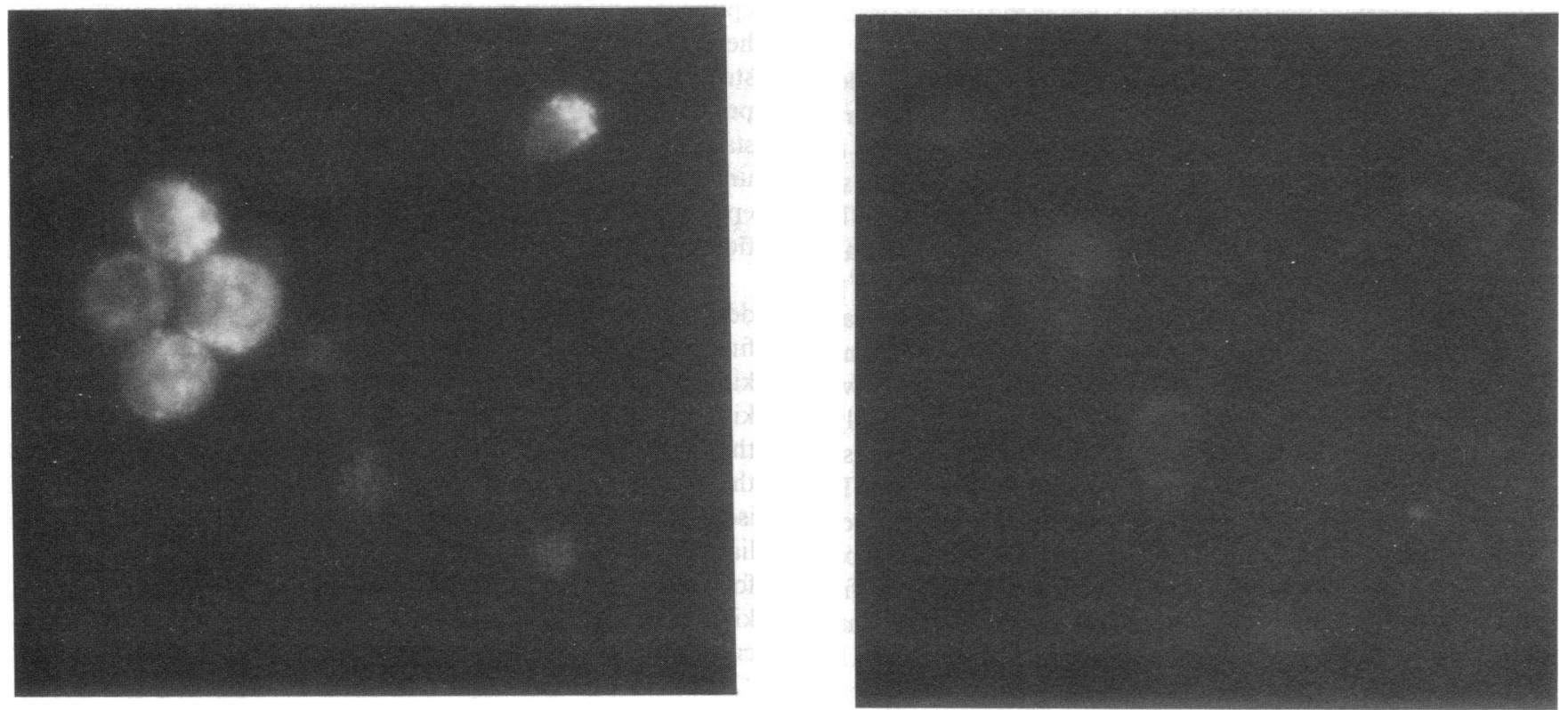

Figure 2. (A) Urinary tract epithelial cells isolated from the irrigation fluid of a healthy human bladder, after stimulation with $E$. coli 83972 . The picture shows staining with anti-IL-8 monoclonal antibodies. $(B)$ Unstimulated epithelial cell control. The picture shows unstimulated epithelial cells after the addition of anti-IL-8 monoclonal antibodies.

Bacterial adhesion and $I L-8$ secretion. The limited number of epithelial cells obtained from bladder irrigation fluid did not allow investigation of the role of fimbriae in the IL-8 response. Epithelial cell lines of urinary tract origin are known to produce IL-8 in response to bacterial stimulation (9). The human kidney (A-498) and bladder (J82) epithelial cell lines were exposed to E. coli 83972, E. coli 1053, and E. coli 1061. Each strain stimulated a significant increase in IL-8 secretion by both cell lines after 6 and $24 \mathrm{~h}$ compared with cells exposed to

Table II. IL-8 Response of Urinary Tract Epithelial Cell Lines to E. coli Stimulation

\begin{tabular}{|c|c|c|c|c|}
\hline Cell line & $\begin{array}{l}\text { E. coli } \\
\text { strains }\end{array}$ & Fimbriae & $\begin{array}{l}\text { Adherence* } \\
\text { to cell lines }\end{array}$ & IL-8 response ${ }^{\ddagger}$ \\
\hline & & & & $n g / m l, 24 h$ \\
\hline \multirow[t]{5}{*}{ A-498 } & - & - & & $0.18(0.31)$ \\
\hline & 83972 & - & 0.2 & $2.12(0.63)$ \\
\hline & Hu 1061 & $\mathbf{P}$ & 0.3 & $1.95(0.52)$ \\
\hline & Hu 1053 & Type 1 & $>100$ & $4.32(0.94)$ \\
\hline & & (mannose) $^{\S}$ & 0.3 & $1.78(0.50)$ \\
\hline \multirow[t]{5}{*}{$\mathrm{J} 82$} & - & & & $1.26(0.59)$ \\
\hline & 83972 & - & 0.2 & $4.56(1.73)$ \\
\hline & Hul061 & $\mathbf{P}$ & 3.4 & $8.90(3.36)$ \\
\hline & Hul053 & Type 1 & $>100$ & $14.50(5.41)$ \\
\hline & & $(\text { mannose })^{\S}$ & 0.3 & $3.20(2.55)$ \\
\hline
\end{tabular}

* Mean number of adhering bacteria per epithelial cell (40 cells counted). ${ }^{\ddagger}$ Mean of seven experiments with the standard error given in brackets. ${ }^{8} \mathrm{IL}-8$ secretion in response to E. coli $\mathrm{Hu} 1053$ when in the presence of $\alpha$-methyl-D-mannoside (three experiments). medium alone (Table II). The J82 cells secreted significantly more IL-8 than the A-498 cells at $24 \mathrm{~h}$ of stimulation with $E$. coli $83972(P<0.014)$ and $E$. coli $1061(P<0.023)$. The levels of IL-8 secreted by the urinary tract epithelial cell lines depended on the adherence characteristics of the bacterial strain used for stimulation. E. coli 83972 did not attach to the J82 or A-498 cells, however, it stimulated these cells to secrete significantly higher levels of IL-8 than medium alone. E. coli 1053 (type 1 fimbriated) adhered to the J82 and A-498 cells and stimulated an IL-8 response in both cell lines which was signifcantly higher than that elicited by $E$. coli $\mathrm{Hu} 1061(P<0.014$ and $P<0.014)$ and $E$. coli $83972(P<0.009$ and $P<0.014)$. This IL-8 response was reduced in both cell lines by the addition of $\alpha$-methyl-D-mannoside ( Table II). E. coli 1061 (P fimbriated) adhered to the $\mathrm{J} 82$ cells and stimulated a significantly higher IL-8 response in these cells than $E$. coli 83972 ( $P$ $<0.009$ ). E. coli 1061 did not adhere to the A-498 cells and did not stimulate higher levels of IL-8 secretion than E. coli 83972 in these cells.

\section{Discussion}

This study focused on the mucosal IL-8 response to UTI. The IL-8 response was analyzed in patients deliberately colonized in the urinary tract with $E$. coli IL-8 was not detected in the urine before colonization, however, IL-8 was secreted into the urine by all patients after bacterial instillation. IL-8 was not detected in serum. The results suggested that IL-8 was produced locally by cells at the mucosa. Epithelial cells are the first host cell to interact with bacteria, and they are known to produce cytokines $(9,13)$. We therefore analyzed whether urinary tract epithelial cells were a possible source of urinary IL-8. The colonization strain E. coli 83972 stimulated exfoliated uroepi- 
thelial cells and epithelial cell lines to produce IL-8 in vitro. The fimbriated and adhering transformant $E$. coli strains 1053 and 1061 stimulated a higher IL-8 response than the parent strain. We consider uroepithelial cells lining the urinary tract as likely sources of IL-8 in patients with UTI.

Despite the fact that most Gram-negative bacteria reside at mucosal surfaces, and that invasion of systemic sites is a rare event, the human IL-8 response to mucosal infection has not been investigated. Previous studies have focused on the systemic IL-8 response to Gram-negative bacteria and LPS. IL-8 was detected in the serum of human volunteers after intravenous endotoxin administration (14), and in the plasma of patients during Gram-negative bacteremia (16). IL-8 has also been found in the plasma of baboons after intravenous infusion with $E$. coli (17). The treatment of recurrent UTI with nonvirulent bacteria provided a unique opportunity to analyse the mucosal response to $E$. coli. The patients in this study suffered recurrent UTI due to neurogenic bladder disorders. The outcome of the bacterial colonization has been described previously (12). The $E$. coli strain 83972 established persistent bacteriuria in all of the colonized individuals. In contrast, the fimbriated isogenic $E$. coli strains 1053 and 1061 were eliminated within $48 \mathrm{~h}$. The patients did not develop symptoms of UTI and there were no changes in systemic host response parameters like C-reactive protein or erythrocyte sedimentation rate. Furthermore the patients were protected from superinfection for as long as bacteriuria remained. The IL-8 response in these patients was examined before and after bacterial instillation. In this way it was possible to attribute the changes in IL-8 levels to the bacterial instillation, rather than variables such as the underlying illness of the patient.

Mucosal surfaces have only recently become recognized as sites of cytokine production $(11,18)$. Samples from the colonized patients provided important early evidence of mucosal cytokine production (11). Colonization stimulated the secretion of IL- 6 into the urine, but there was no elevation of serum IL-6 levels. The results of the present study demonstrated that stimulation of the urinary tract mucosa with $E$. coli elicited the secretion of IL-8 into the urine without an elevation of serum IL-8. There were several differences in the IL-6 and IL-8 responses in the patients. First, levels of IL-6 detected in the urine were similar in all the colonized patients, whereas the IL-8 response varied greatly from individual to individual. Second, the IL-6 secretion was influenced by the concentration of bacteria in the urines. Significantly higher IL-6 levels were observed at bacterial concentrations greater than $10^{5}$ bacteria per $\mathrm{ml}$. Urinary IL- 8 levels were not influenced by the bacterial concentration. Third, IL- 8 but not IL- 6 showed a strong correlation with the urinary neutrophil numbers.

The correlation between urinary IL- 8 levels and neutrophil numbers in the present study indicated that neutrophils may secrete IL-8 during UTI. It is now well established that neutrophils are a source of IL-8. IL-8 production has been observed in phagocytosing neutrophils and in neutrophils stimulated with LPS and $\mathrm{MLP}(19,20)$. The $E$. coli strains studied here stimulated neutrophil IL-8 production in vitro (W. Agace, unpublished observation). The mechanism of this stimulation, whether a result of bacterial phagocytosis or nonphagocytic stimulation by factors such as LPS, remains unknown.

The analysis of the early urinary IL-8 response in the patients showed that IL-8 was present in urine before the neutro- phil influx. Bacteria which reach the urinary tract first interact with epithelial cells in the mucosal lining. To examine the role of epithelial cells as a source of IL-8, we isolated urinary tract epithelial cells from the bladder irrigation fluid of patients with healthy bladders, undergoing cytoscopy for bladder neck obstruction. Bacteria stimulated the bladder epithelial cells to produce IL-8 in vitro. More than $70 \%$ of the epithelial cells stained intracellularly for IL-8 after $E$. coli stimulation. The unstimulated cells did not stain for IL-8. This suggested that epithelial cells may be a source of IL-8 after bacterial stimulation at the onset of UTI.

The limited number of epithelial cells obtained from bladder irrigation samples did not allow investigation of the role of fimbriae in the epithelial IL-8 response. Human bladder and kidney epithelial cell lines have been shown to produce cytokines including IL-8 after stimulation with bacteria $(9,21)$. We therefore examined the IL-8 response of the urinary tract epithelial cell lines to the three $E$. coli colonization strains. The isogenic $E$. coli strains differed in their adherence to the epithelial cell lines and their ability to elicit IL-8 secretion. The transformant $E$. coli 1053 , expressing type 1 fimbriae, adhered to kidney and bladder epithelial cell lines and stimulated the secretion of higher levels of IL-8 than the nonfimbriated parent $E$. coli 83972, and the P fimbriated transformant $E$. coli 1061. Both adherence of $E$. coli 1053 and induction of IL-8 production were reduced by $\alpha$-methyl-D-mannoside; a competitive inhibitor of type 1 fimbrial binding. The transformant $E$. coli 1061, which expressed $P$ fimbriae, adhered to the bladder epithelial cell line and elicited a higher IL-8 secretion in these cells than the nonfimbriated parent $E$. coli 83972 . These results suggested that adherence enhances the epithelial IL-8 response to bacteria. Two possible mechanisms for the adherence enhanced cytokine response have been discussed. LPS has been shown to stimulate IL-8 (W. Agace, unpublished data) and IL-6 production in epithelial cell lines (13). The close proximity of the adhering bacteria to the epithelial cell surface may increase the local concentration of LPS. There is also evidence that direct adhesin-receptor interaction may lead to epithelial cell cytokine production. Isolated $P$ fimbriae with the adhesin stimulated an IL-6 response in the kidney epithelial cells, while fimbrial proteins lacking the adhesin did not (13).

The influx of neutrophils during UTI suggests there is a release of neutrophil chemoattractants at the mucosa. IL-8 is one well characterized neutrophil chemoattractant. The results of this study show that IL-8 is secreted rapidly at the onset of UTI. Epithelial IL-8 production occurs after stimulation with bacteria. The production of IL-8 by epithelial cells and neutrophils in response to bacteria may also be induced by the release of cytokines by cells at the mucosa. Epithelial cells secrete IL-8 in response to IL- $1 \alpha$ and TNF $\alpha$ (Hedges, S. R., W. W. Agace, and C. Svanborg, manuscript submitted for publication). Neutrophils produce cytokines in response to other cytokines (22). The levels of IL-8 production during UTI are therefore likely to be modified in a mucosal cytokine network. The production of IL- 8 by the urinary tract epithelial mucosa may play a role in the neutrophil influx observed during UTI. It is also likely that a number of other chemotactic molecules, including bacterially produced $f M L P$, lipid metabolites $\left(\mathrm{LTB}_{4}\right)$, and products of complement ( $\mathrm{C} 5 \mathrm{a}$ ), are released at the mucosa. The role of these molecules on the neutrophil influx during UTI has not yet been determined. 


\section{Acknowledgments}

The authors thank Sandoz Research, Vienna, Austria, for their kind gift of antibodies for the IL-8 ELISA and immunofluorescent staining. These studies were supported by The Medical Faculty, University of Lund, The Swedish Medical Research Council (grant 7934), and the Österlund and Crawford foundations.

\section{References}

1. Baggiolini, M., A. Walz, and S. L. Kunkel. 1989. Neutrophil-activating peptide-1/interleukin-8, a novel cytokine that activates neutrophils. J. Clin. Invest. $84: 1045-1049$.

2. Willems, J., M. Joniau, S. Cinque, and J. van Damme. 1989. Human granulocyte chemotactic peptide (IL-8) as a specific neutrophil degranulator; comparison with other monokines. Immunology. 67:540.

3. Smith, W. B., J. R. Gamle, I. Clark-Lewis, and M. A. Vadas. 1991. Interleukin-8 induces neutrophil transendothelial migration. Immunology. 72:65-72.

4. Walz, A., F. Meloni, I. Clark-Lewis, V. von Tscharner, and M. Baggiolini. 1991. $\left(\mathrm{Ca}^{2+}\right)_{i}$ Changes and respiratory burst in human neutrophils and monocytes induced by NAP-1/IL-8, NAP-2, and gro/MGSA. J. Leukocyte Biol. 50:279-286.

5. Colditz, I. G., R. D. Zwahlen, and M. Baggiolini. 1990. Neutrophil accumulation and plasma leakage induced in vivo by neutrophil-activating peptide-1. J. Leukocyte Biol. 48:129-137.

6. Follin, P., M. P. Wymann, B. Dewald, M. Ceska, and C. Dahlgren. 1991. Human neutrophil migration into skin chambers is associated with production of NAP-1/IL-8 and C5a. Eur. J. Haematol. 47:71-76.

7. Strieter, R. M., S. L. Kunkel, H. J. Schowell, G. D. Remick, S. H. Phan, P. A. Ward, and R. M. Marks. 1989. Endothelial cell gene expression of a neutrophil chemotactic factor by TNF, IL-1 and LPS. Science (Wash. DC). 243:1467.

8. Standiford, T. J., S. L. Kunkel, M. A. Basha, S. W. Chensue, J. S. Lynch, G. B. Toews, J. Westwick, and R. M. Strieter. 1990. Interleukin-8 gene expression by a pulmonary epithelial cell line. A model for cytokine networks in the lung. $J$. Clin. Invest. 86:1945-1953.

9. Agace, W., S. Hedges, U. Andersson, J. Andersson, M. Ceska, and C. Svanborg. 1993. Selective cytokine production by epithelial cells following exposure to E. coli. Infect. Immun. 61:602-609.

10. Hedges, S., K. Stenqvist, G. Lidin Janson, T. Sandberg, and C. Svanborg. 1992. Comparison of urine and serum concentrations of interleukin- 6 in women with either acute pyelonephritis or asymptomatic bacteriuria. J. Infect. Dis. 166:653-656.

11. Hedges, S., P. Anderson, G. Lidin-Janson, P. de Man, and C. Svanborg. 1991. Interleukin-6 response to deliberate colonization of the human urinary tract with gram-negative bacteria. Infect. Immun. 59:421-427.

12. Andersson, P., I. Engberg, G. Lidin-Janson, K. Lincoln, R. Hull, S. Hull, and C. Svanborg. 1991. Persistence of Escherichia coli bacteriuria is not determined by bacterial adherence. Infect. Immun. 59:2915-2921.

13. Hedges, S., M. Svensson, and C. Svanborg. 1992. Interleukin-6 response of epithelial cell lines to bacterial stimulation in vitro. Infect. Immun. 60:12951301.

14. Martich, G. D., R. L. Danner, M. Ceska, and A. F. Suffrendini. 1991. Detection of interleukin-8 and tumor necrosis factor in normal humans after intravenous endotoxin: the effect of antiinflammatory agents. J. Exp. Med. 173:771-774.

15. Sander, B., J. Andersson, and U. Andersson. 1991. Assessment of cytokines by immunofluorescence and the paraformaldehyde-saponin procedure. Immunol. Rev. 119:65-93.

16. Friedland, J. S., Y. Suputtamongkol, D. G. Remick, W. Chauwagul, R. B. Strieter, S. L. Kunkel, N. J. White, and G. E. Griffin. 1992. Prolonged elevation of interleukin-8 and interleukin-6 concentrations in plasma and of leukocyte interleukin-8 mRNA levels during septicemic and localized Pseudomonas pseudomallei infection. Infect. Immun. 60:2402-2408.

17. van Zee, K. J., E. Fischer, A. S. Hawes, C. A. Hebert, T. G. Terrell, J. B. Baker, S. F. Lowry, and L. L. Moldawer. 1992. Effects of intravenous IL-8 administration in non-human primates. J. Immunol. 148:1746-1752.

18. de Man P, C. van Kooten, L. Aarden, I. Engberg, H. Linder, and C. Svanborg-Edén. 1989. Interleukin-6 induced at mucosal surfaces by Gram-negative bacterial infection. Infect. Immun. 57:3383-3388.

19. Cassatella, M. A., F. Bazzoni, M. Ceska, I. Ferro, M. Baggiolini, and G. Berton. 1992. The chemoattractant formyl-methionyl-leucyl-phenylalanine induces the gene expression and release of IL-8 through a pertussis toxin-sensitive pathway. J. Immunol. 148:3216-3220.

20. Bazzoni, F., M. A. Cassatella, F. Rossi, M. Ceska, B. Dewald, and M. Baggiolini. 1991. Phagocytosing neutrophils produce and release high amounts of the neutrophil-activating peptide 1/interleukin 8. J. Exp. Med. 173:771-774.

21. Hedges, S., P. de Man, H. Linder, C. van Kooten, and C. Svanborg-Edén. 1990. Interleukin-6 is secreted by epithelial cells in response to Gram-negative bacterial challenge. In Advances in Mucosal Immunology. International Conference of Mucosal Immunity. Kluwer Academic Publishers, T. MacDonald, editor. London. 144-148.

22. Lloyd, A. R., and J. J. Oppenheim. 1992. Poly's lament: the neglected role of the polymorphonuclear neutrophil in the afferent limb of the immune response. Immunol. Today. 13:169-172. 